Brit. J. industr. Med., 1954, 11, 235.

\title{
CARBON DISULPHIDE POISONING IN VISCOSE RAYON FACTORIES *
}

\author{
BY \\ ENRICO C. VIGLIANI \\ From the Institute for Industrial Medicine, University of Milan
}

(RECEIVED FOR PUBLICATION JUNE 18, 1954)

The manufacture of rayon by the viscose process exposes workers to the hazards of carbon disulphide $\left(\mathrm{CS}_{2}\right)$ poisoning. When the viscose industry was started the toxicity of carbon disulphide was scarcely known among manufacturers, and the processes used were primitive; this resulted in many cases of $\mathrm{CS}_{\mathbf{2}}$ poisoning in all those countries where viscose plants had been established. Since then, technicians, besides trying to increase and improve production, have had to solve the problem of protecting workers against the hazards of $\mathrm{CS}_{2}$.

Italy was one of the first countries to undertake the production of rayon and staple yarn by the viscose process. Until 1936 Italy was one of the leading European producers of rayon and staple. This industry was afterwards greatly developed in other countries and Italy now ranks third; the output in 1951, however, was 137,000 tons, that is, one-fifteenth of the world's production (Viviani and Graziano, 1952).

The viscose industry in Italy employs at present over 20,000 workers ; unfortunately, there are still cases of carbon disulphide poisoning, but since the beginning of the industry the clinical features of the intoxication have undergone a marked change.

The greatest expansion in the viscose industry in Italy was from 1924 to 1927 , during which period production was trebled, increasing from 8,000 to 26,000 tons. In those years the limited preventive measures and the frequent modifications of processes must have caused many cases of intoxication, but, since $\mathrm{CS}_{2}$ poisoning was not a compensatable occupational disease until 1934, we have no available data as to its incidence.

In 1933, Ranelletti collected in a monograph 80 published cases of carbon disulphide poisoning which had occurred in Italy. The incidence of symptoms

* Based on a paper read at the XIth International Congress on Industrial Medicine, Naples, 1954.

B was acute psychosis $52 \%$, anaemia and exhaustion $17 \%$, polyneuritis $17 \%$. In newer statistics by Ranelletti, published in 1935, the percentage of polyneuritis had increased to $25 \%$.

Between 1928 and 1934 Quarelli and his colleagues described some cases of Parkinson's disease and other extrapyramidal syndromes as due to carbon disulphide poisoning.

At the eleventh Italian Congress of Industrial Medicine in 1934 Quarelli stated that he had seen many cases of poisoning in the previous few years. Symptoms of the disease were a decrease of muscular strength, and sexual weakness, hypo-excitability of the nerves and muscles, particularly the peroneus, and, in almost $30 \%$ of the cases, signs of extrapyramidal involvement. The existence of an extrapyramidal syndrome in carbon disulphide poisoning was later acknowledged and confirmed by others, not only in Italy. In the United States, Hamilton and Lewy (1939) collected 120 cases of poisoning, $33 \%$ of which showed extrapyramidal symptoms ; Gordy and Trumper (1938) described 21 cases of poisoning, five of which involved extrapyramidal symptoms.

Statistics of the Italian Institute for Insurance against Accidents and Occupational Diseases show that from 1934 to 193783 cases of carbon disulphide poisoning received compensation ; the majority of them occurred in viscose factories. Owing probably to the large increase in the production of staple yarn, in 1938 alone there were 83 cases, of which one was fatal and 16 involved permanent disability.

I had the opportunity of dealing with all the cases of carbon disulphide poisoning which occurred during 1940 and 1941 in Piedmont, where five viscose plants were operated by a total of 10,000 workers. During that period, because of the war, the production of rayon and staple was pushed to the maximum, and, together with the " black-out ", 
diminished ventilation in the rooms, lengthened working hours up to 10 or 12 per day, and improper methods of handling then used for transferring the staple from the washing to the bleaching machines, outbreaks of carbon disulphide poisoning occurred in two of the largest plants*. I myself observed 100 cases. The incidence of $\mathrm{CS}_{2}$ poisoning and $\mathrm{CS}_{2}$ concentrations in the most hazardous section of the two plants at the end of 1941 are shown in Table 1.

\section{TABLE 1}

DISTRIBUTION OF 100 CASES OF POISONING OBSERVED IN 1943-41 AND CS ${ }_{2}$ CONCENTRATION IN TWO PLANTS

\begin{tabular}{|c|c|c|c|c|}
\hline \multirow{2}{*}{ Department } & \multirow{2}{*}{$\begin{array}{l}\text { No. of } \\
\text { Cases }\end{array}$} & \multicolumn{3}{|c|}{$\mathrm{CS}_{2}$ Concentration (mg./1.) } \\
\hline & & Average & Maximum & Minimum \\
\hline $\begin{array}{l}\text { Churn } \ldots \\
\text { Staple spinning } \ldots \\
\text { Staple bleaching } \\
\text { Rayon bobbin washing. } \\
\text { Others .. }\end{array}$ & $\begin{array}{r}11 \\
9 \\
71 \\
5 \\
4\end{array}$ & $\begin{array}{l}0.45 \\
0 \cdot 60 \\
1.00 \\
0.45 \\
-\end{array}$ & $\begin{array}{l}0 \cdot 87 \\
1.00 \\
2 \cdot 50 \\
0 \cdot 75 \\
-\end{array}$ & $\begin{array}{l}0 \cdot 11 \\
0 \cdot 22 \\
0.00 \\
0 \cdot 15 \\
-\end{array}$ \\
\hline
\end{tabular}

In the staple bleaching rooms workers discharging the washing machines and feeding the bleaching machines, as well as those cleaning the gully gratings, were exposed for four to five hours a day to $\mathrm{CS}_{2}$ concentrations of 1.0 to $2.0 \mathrm{mg}$./1. No cases occurred in rooms where the $\mathrm{CS}_{2}$ concentration was below $0 \cdot 15$ to $0.20 \mathrm{mg}$. $/ 1$.

From the study of the relationship between the $\mathrm{CS}_{2}$ content of the air and the occurrence of poisoning, I was led to the following conclusions (Vigliani, 1946):-(1) Concentrations higher than $0.50 \mathrm{mg}$. $/ 1$. with a maximum of $2 \mathrm{mg}$. $/ 1$. are liable to poison workers within four to six months, in some cases in only two months. (2) Concentrations of 0.40 to $0.50 \mathrm{mg}$./1. are apt to cause chronic intoxication after one or more years of work. (3) A few cases of mild poisoning were caused by concentrations of 0.20 to $0.30 \mathrm{mg}$. $/ 1$.

The findings of the outbreak in 1940-41 show a high incidence of polyneuritis, usually localized in the lower limbs. Table 2 shows the most commonly occurring symptoms and their incidence.

Polyneuritis was included only when absence or severe weakening of the Achilles and/or patellar reflexes was found: the symptoms were tiredness and heaviness of the legs, difficulty in walking, pains in the knees, paraesthesias and hypo-aesthesias. Paresis never developed into a complete leg paralysis, and even muscular hypotrophy was never very severe. Many cases of polyneuritis did not improve in the course of years. Zeglio (1946) examined 20

* Similar outbreaks occurred during World War II in many Furopean countries, e.g., in Finland, France, Belgium, Poland, Holland. Germany (Noro, 1944 ; Langelez, 1946; Paluch, 1948; Merlevede, 1951; von der Heydt, 1954).
TABLE 2

INCIDENCE OF SYMPTOMS AMONG 100 CASES OF $\mathrm{CS}_{2}$ POISONING OBSERVED IN 1940-41

\begin{tabular}{|c|c|c|c|c|c|c|}
\hline \multicolumn{6}{|c|}{ Manifestations } & $\%$ \\
\hline Polyneuritis .. ... & $\cdots$ & .. & . & .. & . & 88 \\
\hline Gastric disturbances & .. & .. & .. & .. & .. & 28 \\
\hline Headaches..$\quad \ldots$ & .. & .. & .. & .. & .. & 18 \\
\hline Vertigo $\quad .$. & .. & .. & .. & . & . & 18 \\
\hline Sexual weakness & .. & .. & .. & .. & .. & 16 \\
\hline Tremors $\quad .$. & . & .. & .. & .. & .. & 16 \\
\hline Myopathy & . & .. & .. & .. & .. & 15 \\
\hline Psychoses & .. & .. & .. & .. & . & 5 \\
\hline Extrapyramidal & .. & .. & .. & .. & . & 3 \\
\hline Optic neuritis & .. & .. & .. & .. & . & 2 \\
\hline Hemiparesis & .. & .. & .. & .. & .. & \\
\hline Pseudobulbar paralysis & .. & .. & .. & .. & . & 1 \\
\hline
\end{tabular}

of my cases after five years and found one recovered, four improved, five unchanged, and 10 worse.

Fifteen per cent. of the cases examined showed myopathic symptoms in the calf muscles. Clinically, there was a feeling of heaviness and stiffness of the leg, with hardening and contracture of the calf which made walking very painful. The idiomuscular excitability was increased up to a true myotonic contraction; the muscular chronaxie in these cases was greatly increased, up to a value of 8 to $10 \sigma$. In some patients the myopathic alterations of the calf were really severe. A biopsy was performed on one of the severest cases. Histological examination showed hypertrophy of the muscular fibres, accompanied by atrophy, vacuolar, wax and hyaline degeneration in other fibres, and scars without pericellular fat infiltration. As far as I know, an alteration of this kind had not yet been observed in carbon disulphide poisoning. In two other cases observed in 1953 the clinical diagnosis of myopathy was confirmed by biopsy (Vigliani, 1953).

The first of these two patients (San. E., aged 52) had worked for 26 years in the rayon and staple yarn spinning and washing rooms of Plant P. near Milan. In 1943 he had polyneuritis, but before a complete cure was achieved he returned to his job. In 1953 weakness of the legs with paraesthesia, headaches, gastric disturbances, loss of libido, and painful cramps associated with a feeling of tension and rigidity in the calves. In the morning before getting out of bed he was obliged to massage the calves for some minutes in order to soften them and to avoid cramps. On examination the leg muscles and especially the calves were contracted and very tender and the Achilles reflexes were absent. A biopsy of the calf was performed and showed myopathic alterations (Fig. 1).

In my file of 100 cases seen in 1940-41, five cases were labelled as having $\mathrm{CS}_{2}$ psychosis, but only one case out of five showed acute psychosis. The others had chronic psychoses associated with extrapyramidal symptoms, or mental deterioration connected 


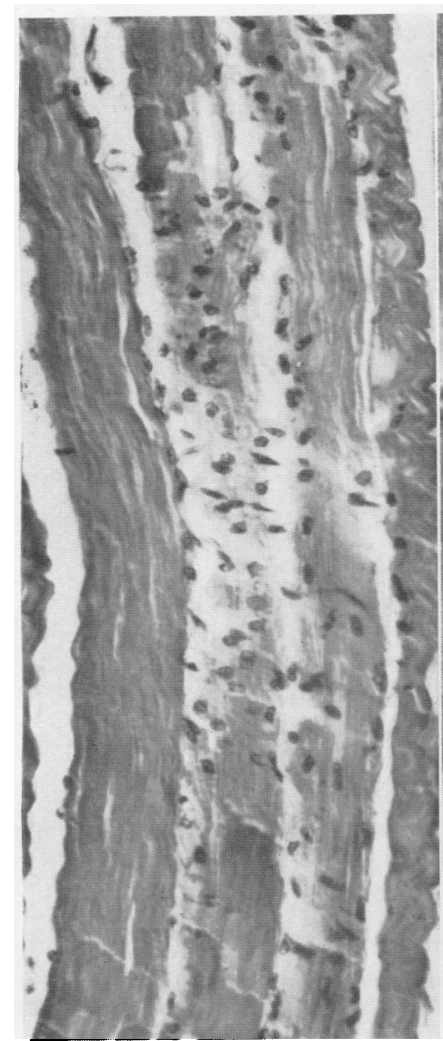

(a)

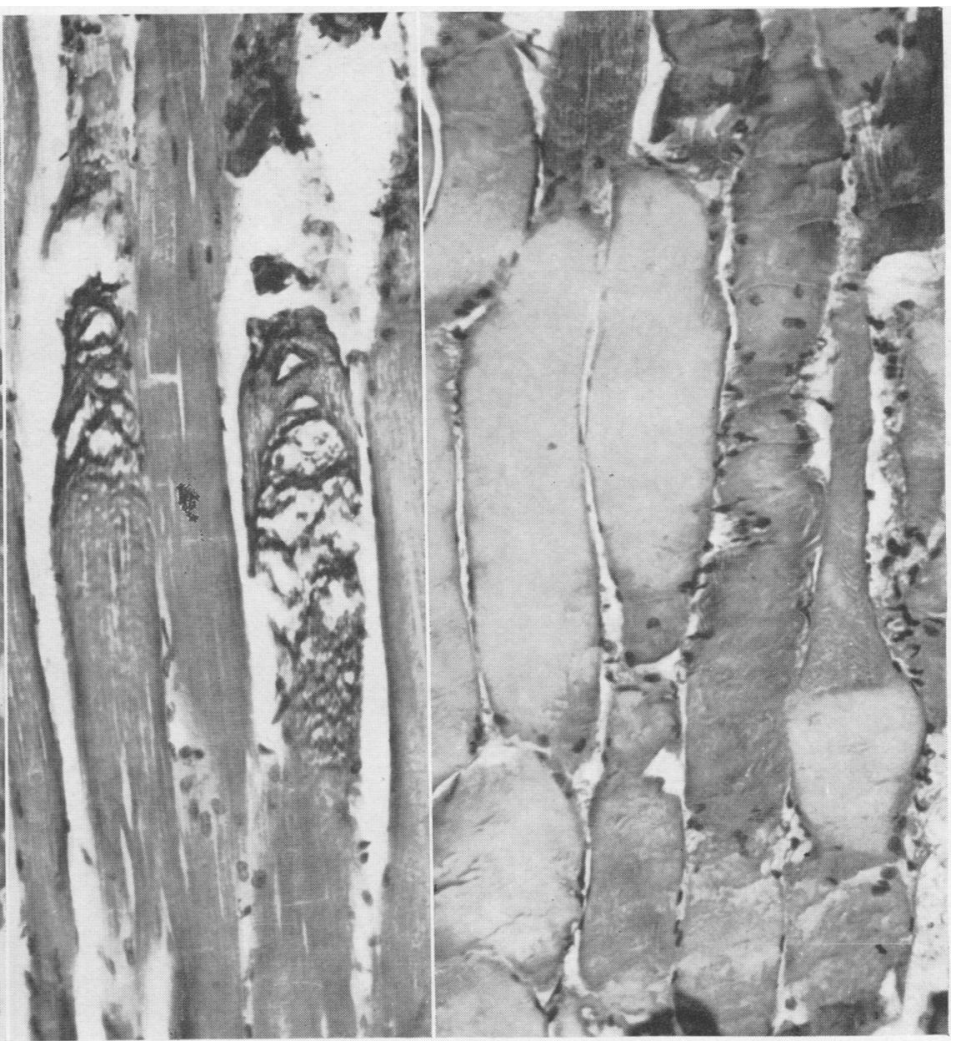

(b) (c)

FIG 1.-Photomicrographs from a biopsy of the gastrocnemius in a cas: of chronic $\mathrm{CS}_{2}$ poisoning with myopathy seen in 1953 (San. E.).

(a) Sarcolemma nuclei invading a muscular fibre $(\times 200)$ : (b) Hydropic-vascular degeneration of two muscular fibres $(x 200) ;$ (c) Swelling and waxy degeneration of muscular fibres $(\times 200)$.

with severe polyneuritis or general manifestations. The case with pseudobulbar paralysis and the case of hemiparesis are very similar to those I frequently observed in the later years; they concerned workers exposed for many years to $\mathrm{CS}_{2}$ and could be considered as cases of vasuclar encephalopathy.

In 1942 I was transferred from Turin to Milan and I have therefore lost sight of the cases of $\mathrm{CS}_{2}$ poisoning in the viscose factories of Piedmont but began examining those from the plants of Lombardy. There were five plants near Milan for the production of viscose, with a total of 8,000 workers. Most of the cases observed, however, came from two plants only. At the start, I again saw some cases of polyneuritis similar to those observed in Turin. Later, the symptomatology and the features of the cases changed into a vascular diffused encephalopathy with or without focal lesions.

The first cases were diagnosed as atherosclerotic dementia, or pseudobulbar paralysis, or diffuse encephalomyelitis, or cerebral thrombosis not of occupational origin. The cases gradually became more frequent and showed certain peculiarities, such as occurrence at a relatively youthful age and long-term exposure to dangerous $\mathrm{CS}_{2}$ concentrations, suggesting a relationship between chronic exposure to $\mathrm{CS}_{2}$ and the occurrence of the disease. Between the years 1943 and 1949 Dr. Cazzullo and I collected and published 16 of such cases (Vigliani and Cazzullo, 1950).

From 1950 to 1953 I have seen an increasing number of similar cases : five in 1950, seven in 1951,13 in 1952, and two in the first quarter of 1953 , so that the total number of cases observed since 1943 is now 43 . Twenty-one came from C. factory, 18 from P. factory, two from a third, and two from a fourth factory ; one patient had worked in three factories.

Table 3 shows the distribution of the cases in the departments of $\mathrm{C}$. and P. factories.

For the 43 workers the average working period by age groups was as in Table 4 . 
TABLE 3

DISTRIBUTION OF 39 CASES OF CHRONIC CS $_{2}$ ENCEPHALOPATHY IN TWO VISCOSE PLANTS DURING 1944-53

\begin{tabular}{|c|c|c|c|c|c|c|}
\hline \multirow[b]{2}{*}{ Department } & \multicolumn{3}{|c|}{ C. Factory } & \multicolumn{3}{|c|}{ P. Factory } \\
\hline & $\begin{array}{c}\text { No. of } \\
\text { Workers }\end{array}$ & $\begin{array}{c}\text { No. } \\
\text { of } \\
\text { Cases }\end{array}$ & $\begin{array}{l}\text { Aver- } \\
\text { age } \\
\text { Years' } \\
\text { Work }\end{array}$ & $\begin{array}{c}\text { No. of } \\
\text { Workers }\end{array}$ & $\begin{array}{c}\text { No. } \\
\text { of } \\
\text { Cases }\end{array}$ & $\begin{array}{l}\text { Aver- } \\
\text { age } \\
\text { Years' } \\
\text { Work }\end{array}$ \\
\hline Rayon spinning and & 225 & 7 & 24 & 229 & 10 & 25 \\
\hline $\begin{array}{l}\text { Staple spinning and } \\
\text { bleaching }\end{array}$ & 180 & 12 & 18 & 55 & 4 & 20 \\
\hline $\begin{array}{c}\text { Churn and viscose } \\
\text { press filters }\end{array}$ & 170 & 2 & 20 & 135 & 4 & 24 \\
\hline Total (average) $\ldots$ & 575 & 21 & (20) & 419 & 18 & (24) \\
\hline
\end{tabular}

TABLE 4

AGE AND YEARS OF WORK OF 43 CASES OF CHRONIC $\mathrm{CS}_{2}$ ENCEPHALOPATHY

\begin{tabular}{c|c|c}
\hline Age & No. of Cases & $\begin{array}{c}\text { Average Years of } \\
\text { Work }\end{array}$ \\
\hline $37-39$ & 4 & 17 \\
$40-49$ & 10 & 19 \\
$50-59$ & 21 & 21 \\
$60-68$ & 8 & 28 \\
\hline Average 52.8 & 43 & 21 \\
\hline
\end{tabular}

In the Appendix 43 cases which I have observed up to the first quarter of 1953 are presented. I have also indicated in each case the degree of disability estimated during the course of clinical studies at the Clinica del Lavoro.

The disease has a most characteristic pattern. There is a slow, deceitful beginning, with paraesthesias, asthenia, difficulty in walking, mental deterioration, spastic paresis, alteration of speech, up to a fully developed pattern of pseudobulbar paralysis. The slow course of the disease was often punctuated by episodes of more or less transient hemiplegia. The history of 25 workers over 43 years of age showed that they had had a stroke, and the examination a spastic hemiparesis. Hemiparesis was found even when the patient had never complained of a stroke. Eleven showed signs of extrapyramidal involvement; of these, six had typical Parkinsonism; one had an alternate MillardGubler syndrome ; one a thalamic syndrome, one a subcortical myokinetic syndrome; two an optic neuritis. The disease has a chronic and progressive course often reaching pseudobulbar paralysis and dementia. Eighteen workers had pseudobulbar paralysis and 15 patients had hypertension. In some cases the blood pressure showed great fluctuations which could easily give way to cerebral accidents ; some had signs of nephrosclerosis.

The symptomatology of all cases, the cerebral arteriography, the electroencephalogram, and the fundus oculi of several revealed that this type of encephalopathy was vascular in nature. The necropsy of three patients, one of whom was only 46 years old, revealed a generalized diffuse vascular sclerosis ; cerebral atherosclerosis was very marked, the hyaline fibrosis of the media, with a halfmoonlike thickening of the intima, in evidence. The brain and the spinal medulla contained many small foci indicative of softening, with a predilection for the basal ganglia caused by the vascular lesions. In one case the kidney has been examined and glomerulosclerotic, Kimmelstiel-Wilson-type lesions were found similar to those observed by Uehlinger (1952) in four cases of chronic vascular damage of the kidney caused by $\mathrm{CS}_{2}$.

Although atherosclerosis was manifest in practically all cases, hypertension and vascular spasms should have contributed in some instances to the development of the cerebral lesions. We are now faced with the problem as to whether these atherosclerotic alterations are caused or at least favoured by the chronic action of carbon disulphide. The answer to this question is not an easy one, because we do not know exactly the cause of atherosclerosis. Certainly, any worker can be struck by cerebral atherosclerosis, especially in old age. There are, however, good reasons for the assumption that the cases I have seen were not caused by simple senile or presenile atherosclerosis, but were connected with the exposure to carbon disulphide. The reasons are as follows.

Almost all the cases have occurred in the spinning rooms and particularly in the rayon vacuum cleaning and staple yarn washing rooms, and in the churn rooms of two factories after an average of 20 years' exposure to the hazard. The $\mathbf{C S}_{2}$ concentration in these departments was, during the period $1938-44$, indubitably higher than 0.20 to $0.30 \mathrm{mg}$. $/ 1$. Determinations carried out in May, 1943, in the C. plant gave concentrations of from 0.65 to 0.80 mg./1. in the churn rooms, from 0.03 to 0.10 in the rayon spinning room, and from 0.20 to 1.5 $\mathrm{mg} . / 1$. in the staple spinning and washing room.

Furthermore, we know that cases of chronic poisoning from $\mathrm{CS}_{2}$, with classical findings of polyneuritis, had been encountered in those departments during the period 1930-43; danger, in the past, had thus been certain and prolonged. From the end of World War II hygienic conditions have greatly improved because of important technical innovations, so that $\mathrm{CS}_{2}$ concentrations to-day are well under $0 \cdot 10 \mathrm{mg}$. $/ 1$.

From my series I have omitted some cases which only presented a hemiplegia and those in patients over 70 years of age. Even with this limitation, 
however, from 1943 up to April, 1953, I have collected 43 cases, 39 of which came from two factories only. In these two factories the churn, spinning, and washing rooms do not employ more than 1,000 workers and out of these only a small portion had been working at the operations for over 10 years. For this reason the percentage of workers struck by diffuse vascular encephalopathy appears to be very high. The true value may be even higher, because it must be considered that I had most probably seen only some of the cases, i.e., those sent to me because of suspected $\mathrm{CS}_{2}$ poisoning.

Cerebral atherosclerosis usually causes clinical manifestations in those over 60 years of age. The average age of my cases was, on the contrary, 53 ; 15 of these were not yet 50. Among the 35 cases under the age of 60,16 had no hypertension, which is commonly associated with presenile cerebral atkerosclerosis. It is, therefore, reasonable to assume the intervention of a toxic factor as well as that of age.

Some pathological and clinical aspects of the cerebral lesions, and particularly the diffusion of the lesions throughout the brain and the marked changes in the nerve cells, support the assumption of a toxic and not a purely atherosclerotic factor.

In some cases the pre-existence or the coexistence of manifestations of typical carbon disulphide poisoning, such as polyneuritis, was established.

Other observations of cases similar to mine, e.g., one case described by Laudenheimer (1899) in a woman aged 32 , the only woman who resisted 10 years' working with $\mathrm{CS}_{2}$; two cases observed by myself in 1940 (Vigliani, 1946), one diagnosed as "pseudobulbar. paralysis due to $\mathrm{CS}_{2}$ ", and one of hemiplegia ; one case of carbon disulphide vascular disease described by Gsell (1948); five cases of " chronic poisoning from $\mathrm{CS}_{2}$ with a pattern of severe vascular disease" observed by Attinger in 1948 ; and two others, altogether similar to my cases, reported by Attinger in 1952; three cases of diffuse cerebral atherosclerosis seen by Dr. Monarca in Piedmont in the last two years; and some described by Nunziante-Cesàro and Luccarelli (1954), reinforced my assumption.

In dogs with chronic $\mathrm{CS}_{2}$ poisoning, Lewey, Alpers, Bellet, Creskoff, Drabkin, Ehrich, Frank, Jonas, McDonald, Montgomery and Reinhold (1941) found severe vascular alterations :

" The marked arteriofibrosis of the cortical blood vessels found in almost all dogs exceeded by far what is usually seen, even in old dogs. Ophthalmoscopic examinations revealed marked angiospasms in the retinal arteries. In other words, chronic exposure to $\mathrm{CS}_{2}$ creates in dogs a tendency to spastic and fibrotic

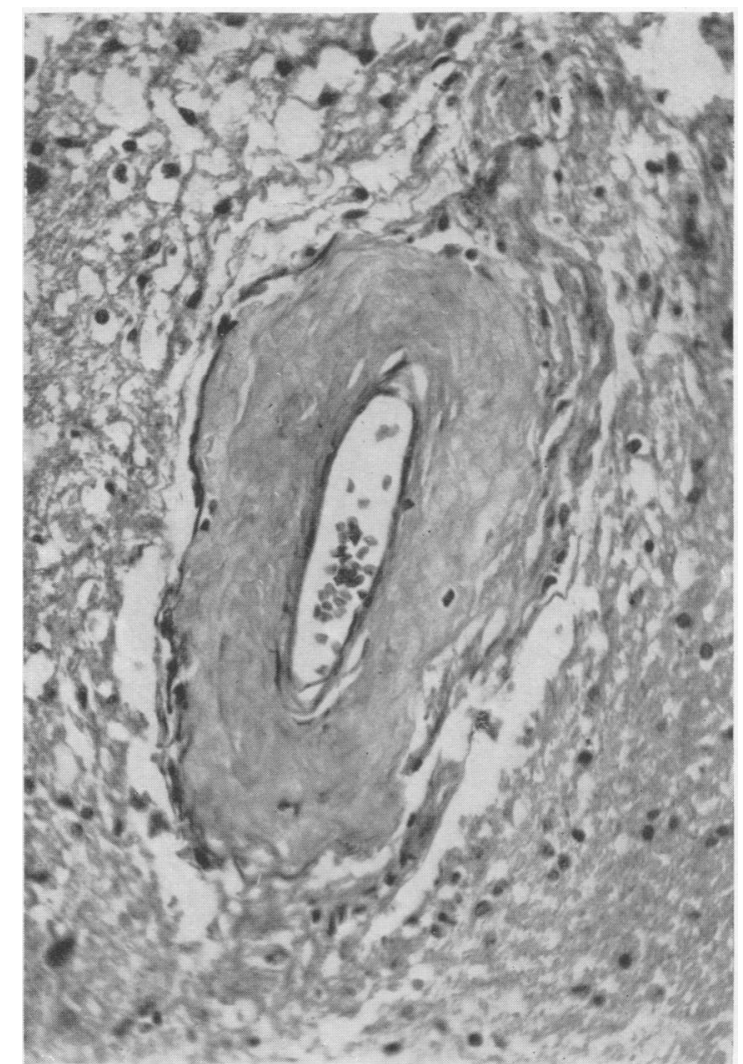

Fig. 2.-Ber. L. (Case 5) aged 42. Pseudobulbar paralysis from $\mathrm{CS}_{2}$. Small arteries of the brain with thickened wall and loss of muscular fibres. Haematoxylin and eosin. $\times 410$.

alterations in the small arteries of the brain and retina. This observation strengthens the probability that high blood pressure in young viscose rayon workers may not be purely coincidental."

In cats poisoned for a period of one to three months with 8 to $10 \mathrm{mg}$. $/ 1$. of $\mathrm{CS}_{2}$ for one to three hours a day, Ferraro, Jervis, and Flicker (1941) found gross alterations of the cortex cerebri vessels, with thrombosis and foci of cerebral weakening; Carratala and Lambre (1951) found also cases of proliferative endovasculitis in various organs of animals poisoned with $\mathrm{CS}_{2}$.

I have exposed for several months albino rats to concentrations of $\mathrm{CS}_{2}$ ranging from 0.4 to 0.6 $\mathrm{mg}$./l. for six hours daily. While the controls did not show vascular lesions, the rats exposed to $\mathrm{CS}_{2}$ gave evidence of initial vascular sclerosis: one rat, which survived for 420 days, showed diffuse and advanced atherosclerosis, similar to that observed in the three human cases cited above. Further experiments are now under way for the 


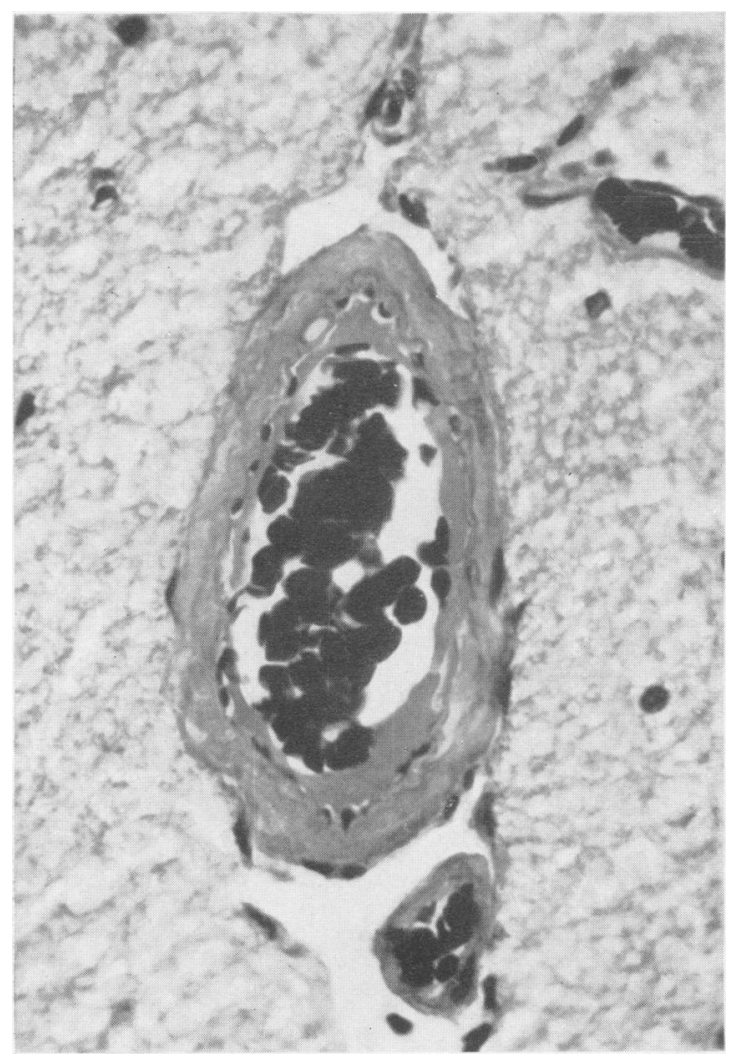

FIG. 3.-Brain of a rat exposed to $0.4-0.6 \mathrm{mg}$./ $/$. for 420 days showing sclerosis of a small artery, with loss of muscle fibres. Haematoxylin and eosin. $\times 590$.

study of atherosclerosis in rats and guinea-pigs exposed to different concentrations of $\mathrm{CS}_{2}$.

Nunziante-Cèsaro, Sipala, and Zunini (1952) have recently confirmed on viscose workers some of the experimental results of Lewey; they frequently saw angiospasms in the retinal arteries accompanied by increased vascular fragility and spasms of the arterial side of the capillaries visible to capillaroscopy.

All these facts support the assumption that a very long exposure to hazardous concentrations of $\mathrm{CS}_{2}$ may cause or greatly enhance a diffuse atherosclerosis of the arterial blood vessels and capillaries, resulting in encephalopathic and/or nephrosclerotic damage. According to this belief, one, and most probably the greatest, section of modern chronic $\mathrm{CS}_{2}$ pathology should be referred to a toxic vasculopathy,

According to the modern views on the pathogenesis of the atherosclerosis, $\mathbf{C S}_{2}$ could interfere with the metabolism of lipoproteins. The deter- mination of the $\beta / \alpha$ lipoprotein ratio carried out in several of our patients gave values as high as 15 , whereas the normal is less than 4. Relatively high ratios have been found also amongst workers exposed for several years to $\mathrm{CS}_{2}$ but without any symptoms : it is possible to conceive that the action of $\mathrm{CS}_{2}$ consists in the inhibition of the clearing factor in the blood, thus preventing the transformation of the more coarsely dispersed $\rho$ lipoproteins in the finely dispersed $\alpha$-lipoproteins.

The discovery of the existence of a chronic vascular encephalopathy from $\mathrm{CS}_{2}$ shows that we must review our opinion on the maximum allowable concentration of $\mathrm{CS}_{2}$ in the air. We had taken as safe concentrations $0.07 \mathrm{mg}$. $/ \mathrm{l}$. of $\mathrm{CS}_{2}$, but are we sure that such a value cannot cause a chronic encephalopathy in 20 to 30 years? The cases I had observed came from plants where concentrations, at least during the war, were very high, and where cases of classical poisoning with polyneuritis were found ; but the four cases observed by Uehlinger (1952) had been exposed for 13 to 25 years to concentrations of $\mathrm{CS}_{2}$ ranging from 0.05 to $0.1 \mathrm{mg}$./l., with occasional exposures as high as $0.15 \mathrm{mg}$./l. The possibility of brain lesions having a chronic course and a delayed appearance as those described in this paper should be a sufficient inducement to improve the control and to fix a very low value for the maximum allowable concentration of $\mathrm{CS}_{2}$.

\section{Summary}

The production of artificial textile fibres by the viscose process exposes workers to the hazard of carbon disulphide $\left(\mathrm{CS}_{2}\right)$ poisoning. During the Second World War many cases of chronic $\mathrm{CS}_{2}$ poisoning occurred in the viscose rayon plants of many European countries including Italy. From 1940 to 1941,100 cases of $\mathrm{CS}_{2}$ poisoning have been observed amongst workers exposed to concentrations ranging from 0.2 to $1.5 \mathrm{mg}$. $/ \mathrm{l}$. in the factories in Piedmont. The most common manifestation observed was polyneuritis $(88 \%$ of the cases), followed by gastric disturbances (28\%), headache and vertigo (18\%), sexual weakness and tremors $(16 \%)$; in $15 \%$ myopathic changes of the calf muscles were noted; in $6 \%$ of the cases mental deterioration, and in 3\% extrapyramidal symptoms were observed.

After the war, working conditions in rayon viscose plants improved considerably so that today it is quite rare to see new cases of carbon disulphide poisoning with classical symptomatology. On the other hand, many cases of chronic vascular encephalopathy developed in workers exposed for 10 to 30 years to atmospheres containing $\mathrm{CS}_{2}$ vapour in 
concentrations which during the war years had been beyond that allowable. Forty-three of such cases seen during the period 1946-53 in four plants in Lombardy are briefly described.

Patients with chronic encephalopathy exhibited symptoms of pseudobulbar paralysis with mental deterioration, frequent extrapyramidal involvement, and focal signs of cerebral thrombosis. Sixteen cases were associated with hypertension and five had kidney insufficiency with albuminuria. Clinical features, electroencephalograms, and cerebral arteriography of several cases and necropsy of three cases revealed that the encephalopathy was vascular in nature and due to a sclerosis of the small arteries and capillaries of the brain and spinal medulla. In one case, a renal glomerulosclerosis of the Kimmelstiel-Wilson type was observed.

Experimental exposure of rats and guinea-pigs for several months to concentrations of $\mathrm{CS}_{2}$ ranging from 0.4 to $0.6 \mathrm{mg}$./1. produced hyperplasia and sclerosis in the media and intima of the brain arterioles. The hypothesis is advanced that prolonged exposure to $\mathrm{CS}_{2}$ can lead to a favourable situation for producing atherosclerosis.

REFERENCES
Attinger, E. (1948). Schweiz. med. Wschr., 78, 667, 815. (1952). Ibid., 82, 829 .
Carratala, R., and Lambre, D. (1951). Rev. As. med., Argentina, 65, 282.

Ferraro, A., Jervis, G. A., and Flicker, D. J. (1941). Arch. Path., Chicago, 32, 723 .

Gsell, O. (1948). Z. Unfallmed. Berufskr., 41, 55.

Gordy, S. T., and Trumper M., (1938). J. Amer. med. Ass., 110 1543.

Hamilton, A., and Lewy, F. H. (1939). Proc. VIII Intern. Congr. Accid. a. Occupat. Diseases, Frankfurt 1938. Thieme, Leipzig, 2, 1107.

Heydt, A. von der (1954). Verh. d. Dtsch. Ges. f. Arbeitsschutz Bd.2, p. 38. Arbeitstagung in Bad Homburg Okt. 1953. D. Sternkopff, Darmstadt.

Langelez (1946). Arch. belges Méd. soc., 4, 67.

Lewey, F. H., Alpers, B. J., Bellet, S., Creskoff, A. J., Drabkin, D. L. Ehrich, W. E., Frank, J. H., Jonas, L., McDonald, R., Montgomery, E., and Reinhold, J. G. (1941). J. Industr. Hyg., 23, 415.

Merlevede, E. (1951). Bijdrage tot de Toxicologie van de zwavelkoolstof. Thesis. Sinte Catharina, Brugge.

Monarca, G. Personal communication.

Noro, L. (1944). Nord. Med., 242015.

Nunziante-Cèsaro, A., and Luccarelli, S. (1954). Folia med., Napoli, 37, No. 4, p. 264.

_, Sipala, E., and Zunini, E. (1952). Ibid, 35, 661.

Paluch, E. A. (1948). J. Industr. Hyg., 30, 37.

Quarelli, G. (1928). Proc. V Int. Congr. Accid. Occupat. Dis., Budapest 1928. Ediz. Cassa Naz. Infort., Roma, 1929, p. 805 .

- (1934). Rass. Previd. Soc., 21, No. 6, p. 5.

Ranelletti, A. (1931). Arch. Gewerbepath. Gewerbehyg., 2, 664.

_- (1933). Il so!focarbonismo professionale. La Grafica Moderna,

Torino. Vogliotti, Torino.

Uehlinger, E. (1952). Schweiz. Z. allg. Path. Bakt., 15, 217.

Vigliani, E. C. (1946). Med. d. Lavoro, 37, 165. (1953). Folia med., Napoli, 36, 144.

- and Cazzullo C. L. (1950). Med. d. Lavoro, 41, 49.

Viviani, E., and Graziano, L. (1952). Fibre artificiali e sintetiche. Einaudi, Torino.

Zeglio, P. (1946). Med. d. Lavoro, 37, 288.

\section{A P P E N D I X}

\section{Case Histories}

Case 1.-Por. C., aged 56, was employed at Plant C. as a spinner for 19 years. He was admitted to hospital in 1943 with scattered neuraxitis with pareto-spastic gait, ataxia, left palpebral ptosis, decrease of strength, very weak Achilles reflexes. Blood pressure was $175 / 90 \mathrm{~mm}$. Hg. Disability was $80 \%$.

Case 2.-Val. B., aged 37, was employed at Plant C. as a spinner for 15 years. He experienced progressive weakness of the legs, diminished vision, difficulty, and then inability to walk, with paraparesis, ataxia, sphincter disorders, and optic subathropia. He was admitted to hospital in 1945 with acute neuraxitic poussée which rapidly worsened and he died.

Case 3.-Soc. G., aged 56, had been a spinning machine cleaner for 20 years. In 1942 came the onset of manifestations with ataxia, headaches, vertigo, apathy, staggering gait, mental deterioration, and loss of memory. He left work in 1942 and was admitted to hospital in
1945 with a pseudobulbar syndrome and in an advanced state of atherosclerotic dementia. Blood pressure was $160 / 60 \mathrm{~mm}$. $\mathrm{Hg}$. The patient died while in the hospital. Necropsy revealed severe cerebral atherosclerosis with lacunar state.

Case 4.-Bas. C., aged 44, had been employed at Plant C. as a staple yarn bleacher for 10 years. In 1945 he had neuraxitis from $\mathrm{CS}_{2}$ with psychosis and reasonless crises of laughter and weeping. He left work in 1945, and was admitted to hospital in 1946 with a pseudobulbar syndrome with a right hemiplegia. Blood pressure was $150 / 95 \mathrm{~mm}$. Hg. He died in the hospital. Necropsy showed diffuse lipoidosic lesions of the arteries and of the cerebral and meningeal veins with two thrombotic foci, one in the right internal capsule and the other in the spinal marrow.

Case 5.-Ber. L., aged 42 , was a spinner for 16 years. He left work in 1940 and was admitted to hospital for the first time in 1940 with a diagnosis of initial 
nephrosclerosis and chronic $\mathrm{CS}_{2}$ poisoning ; in the same year he developed a right hemiplegia. He was readmitted to hospital in 1945 with a typical pseudobulbar syndrome and relative renal insufficiency. Blood pressure was $140 / 80 \mathrm{~mm}$. Hg. Disability was $100 \%$.

Case 6.-Mel. L., aged 37, had been employed at Plant C. as a spinner for 19 years. In 1941 he had polyneuritis from $\mathrm{CS}_{2}$ poisoning; in 1946 weakness and tinglings in the legs. In December, 1946, he had paralysis of the left arm for which he stopped work. He was admitted to hospital in 1947 with a right hemiplegia with hypertension (blood pressure $180 / 110 \mathrm{~mm}$. Hg). While still in the hospital, the patient suffered from an acute glomerulonephritic episode.

Case 7.-Cam. G., aged 47, had been a churner at Plant C. for 20 years. From 1937 he had paraesthesia of the legs and progressive asthenia ; in the latter years decrease of libido. For these disorders he was transferred to the winding department in 1944 . In 1946 he had mental deterioration, loss of memory, and difficulty in walking. He was removed from work in December, 1946, and admitted to hospital in 1947 with diffuse cortical encephalopathy of the pseudobulbar paralysis type with severe psychosis and pareto-spastic gait, and nephrosclerosis with renal insufficiency and hypertension (blood pressure $210 / 130 \mathrm{~mm}$. $\mathrm{Hg}$ ). Disability was $100 \%$.

Case 8.-Oli. G., aged 44, had been employed at Plant C. as a spinner for 14 years. In 1938 he had slight $\mathrm{CS}_{2}$ poisoning, and in 1948 right hemiplegia when he was admitted to hospital. He had slight spastic hemiparesis of the right side with moderate signs of cerebral atherosclerosis, and a blood pressure of 120/70 mm. Hg. Disability was $21 \%$.

Case 9.-Per. F., aged 65, had been a spinner for 25 years in Plant P. From 1946 he suffered from asthenia, difficulty in walking, and giddiness. He left work in 1948, and was admitted to hospital in that year with typical pseudobulbar paralysis with signs of atherosclerotic contracted kidney. Blood pressure was $190 / 125 \mathrm{~mm}$. Hg. Disability was $100 \%$.

Case 10.-Bog. A., aged 45, had been employed at Plant P. as a spinner for 19 years. In 1945 he had a sudden paralysis of the right limbs with difficulty in talking. He was removed from work in 1946, and admitted to hospital in 1948 with classical pseudobulbar paralysis, crises of weeping, and severe mental deterioration. Blood pressure was $190 / 125 \mathrm{~mm}$. Hg. Disability was $100 \%$.

Case 11.-Con. A., aged 51, had been employed at Plant C. as a spinner for 29 years. In September, 1949, he had paresis of the right side for which he left his work. He was admitted to hospital in 1949 with encephalopathy with right motor and coordinatory paresis, and signs of pyramidal and extrapyramidal involvement. Blood pressure was $160 / 110 \mathrm{~mm}$. $\mathrm{Hg}$. Disability was $100 \%$.
Case 12.-Mog. O., aged 48, had been a churner for three years and a rayon bobbin washer for 11 years at Plant P. In 1948 he had $\mathrm{CS}_{2}$ poisoning and left work in October, 1949. He was admitted to hospital in 1949 with a mild right paresis, tremors, psychic depression, initial renal insufficiency, and mild diabetes mellitus. Blood pressure was $170 / 95 \mathrm{~mm}$. Hg. Disability was $40 \%$ :

Case 13.-Mar. I., aged 52, had worked at Plant P. for 24 years at the preparation of the viscose. In June, 1948, he had a motor deficit of the hands for which he was removed from work and admitted to the Neurological Hospital at Pavia. In 1949 he was admitted to this Institute with a pseudobulbar syndrome with a mild state of dementia, dysarthria, left facial paresis. Blood pressure was $175 / 90 \mathrm{~mm}$. $\mathrm{Hg}$. Disability was $100 \%$.

Case 14.-Mal. L., aged 57, had worked at Plant P. as a spinner for 28 years, and as a rayon bobbin washer for two years. In 1946 heaviness of the legs, with progressive functional loss led to severe difficulty in walking. He left work in 1948 and was admitted to hospital in 1949 with a pseudobulbar syndrome with dysarthria, mental deterioration, extrapyramidal hypertonia, and spastic paraparesis. Blood pressure was $150 / 100 \mathrm{~mm}$. $\mathrm{Hg}$. Disability was $100 \%$.

Case 15.-Mor. E., aged 54, had been employed at Plant $P$. as a spinner for 12 years and as a rayon bobbin washer for five years. In December, 1948, he had a stroke with right hemiplegia for which he left his work. He was admitted to hospital in 1949 with multiple encephalopathic lesions with right hemiplegia, dysarthria, pyramidal and extrapyramidal hypertonia, blood pressure varying from $185 / 130$ to $150 / 90 \mathrm{~mm}$. $\mathrm{Hg}$. Disability was $100 \%$.

Case 16.-Cav. P., aged 58, had been a rayon bobbin washer for 14 years at Plant C. In April, 1949, he had a slight transitory right-sided stroke. He left work in 1949, and was admitted to hospital in 1950 with a mild right spastic paresis. Blood pressure was 190/110 mm.Hg. Disability was $25 \%$.

Case 17.-Cor. L., aged 68, had worked at Plant P. as a spinner for 28 years, and as a rayon bobbin washer for 10 years. In 1947 he had signs of polyneuritis with difficulty in walking for which he left work. He went downhill and was admitted to hospital in 1950 with severe subcortical diffuse neuraxitis of the pseudobulbar paralysis type. Blood pressure was $170 / 110 \mathrm{~mm}$. $\mathrm{Hg}$. Disability was $100 \%$.

Case 18.-Lod. G., aged 60, had been a churner at Plant C. for 20 years. In 1947 he had polyneuritis of the legs and left work in 1950. He was admitted to hospital in that year with diffuse encephalopathy with corpus-striatum localization (subcortical myokinetic syndrome) with abulia, mental deterioration, amimia, tremors, hyperreflectivity. Blood pressure was 185/100 mm. Hg. Disability was $100 \%$. 
Case 19.-Par. L., aged 60 had worked at Plant P. as a spinner for 23 years. In 1948 he had a stroke with right paresis for which he left work. In 1949 he had another stroke and aggravation of the paresis. He was admitted to hospital in 1950 with mild right hemiparesis with signs of slight extrapyramidal involvement. Blood pressure was $200 / 120 \mathrm{~mm}$. $\mathrm{Hg}$. He had a moderate loss of the ability to concentrate urine. Disability was $40 \%$.

Case 20.-Ace. E., aged 64, had been employed at Plant P. as a spinner for 30 years. In January, 1950, he had a sudden mild right paresis for which he was removed from work and admitted to the Neurological Hospital of Pavia with a diagnosis of hemiplegic-like pseudobulbar paralysis. At this Institute in 1950 mild pseudobulbar paralysis with moderate loss of power due to a right hemisyndrome was found, blood pressure varying from $140 / 90$ to $110 / 70 \mathrm{~mm}$. $\mathrm{Hg}$. Disability was $21 \%$.

Case 21.-Fer. C., aged 39, had been a churner for seven years, a spinner and bleacher for eight years at Plant P. From 1941 he had heaviness of the legs and paraesthesias. In 1950 he had tremor and pains in the legs, pareto-spastic gait, and mental deterioration for which he left work. He was admitted to hospital in 1951 with a disseminated sclerosis type of neuraxitis. Blood pressure was $130 / 90 \mathrm{~mm}$. Hg. Disability was $80 \%$.

Case 22.-Cas. A., aged 47 , had worked at Plant $\mathbf{P}$. as a spinner for eight years, and as a rayon bobbin washer for 20 years. In 1949 he had polyneuritis of the lower limbs, and in 1951 right hemiparesis for which he left work. He was admitted to hospital in 1951 with subcortical encephalopathy with left hemiparesis, moderate loss of the ability to concentrate urine, and an encephalogram positive for diffuse cerebral angiopathy. Blood pressure was $130 / 80 \mathrm{~mm}$. Hg. Disability was $80 \%$.

Case 23.-Mor. G., aged 63, had been a spinner at Plant C for 30 years. In 1949 he had signs of polyneuritis (pains, paraesthesias, staggering gait). He was removed from work in October, 1950, and admitted to hospital in 1951 with diffuse encephalopathy with spastic paraparesis, amimia, mental dullness, tremors. Blood pressure was $160 / 100 \mathrm{~mm}$. $\mathrm{Hg}$, with oscillations to $220 / 110$. Disability was $80 \%$.

Case 24.-Zam. L., aged 57, had been a rayon bobbin washer for 24 years at Plant P. In April, 1951, he had sudden mental confusion followed by right paresis. He stopped work in April, 1951, and was admitted to hospital in 1951 with diffuse vascular encephalopathy in evolution, with right motor hemisyndrome, optic subatrophy, mild polyneuritis of the legs. An electroencephalogram was indicative of diffuse vascular lesions. Disability was $100 \%$.

Case 25.-Res. A., aged 58, had worked at Plant $\mathbf{M}$. as a spinner for seven years, and as a churn cleaner for three years. In 1949 he had mild polyneuritis from $\mathrm{CS}_{2}$, left work in October, 1950, and was admitted to hospital in 1951 with polyneuritis of the legs, amimia, and moderate psychic loss. Blood pressure was $140 / 100$ mm. Hg. Disability was $21 \%$.

Case 26.-Vag. C., aged 52, had worked at Plant C. as a churner for 10 years and as a viscose filter cleaner for 10 years. In 1949 he had polyneuritis from $\mathrm{CS}_{2}$. He was removed from work in 1950 and admitted to hospital in 1951 with diffuse encephalopathy with mild right hemiparesis and signs of polyneuritis in the legs. Blood pressure was $160 / 100 \mathrm{~mm}$. Hg. Disability was $80 \%$.

Case 27.-Qua. L., aged 59, had been a spinner for 27 years at Plant C. In 1949 he had a right transient hemiparesis then again deficit of the right side, pains, asthenia. He left work in December, 1950, and was admitted to hospital in 1951 with moderate loss of power of the right side. Blood pressure was $125 / 90 \mathrm{~mm}$. $\mathrm{Hg}$. Disability was $21 \%$.

Case 28.-Gro. L., aged 55, had worked at Plant C. as a spinner for two years and as a rayon bobbin washer for 13 years. From 1947 he had heaviness of the legs with progressive difficulty in walking. He left work in May, 1951, and was admitted to hospital in 1952 with diffuse encephalopathy with symptoms of loss of power, mainly of the right side, mental deterioration, and dysarthria. Blood pressure was $160 / 90 \mathrm{~mm}$. Hg. Disability was $60 \%$.

Case 29.-Gab. M., aged 56, had worked at Plant P. at the viscose filtering operations for 26 years. In 1932 he had $\mathrm{CS}_{2}$ polyneuritis of the legs and in 1950 subacute $\mathrm{CS}_{2}$ poisoning. He left work in November, 1952, and was admitted to hospital in 1952 with diffuse encephalopathy of the pseudobulbar paralysis type with spastic paraparesis, crises of weeping, loss of memory, and giddiness. Blood pressure was $140 / 80 \mathrm{~mm}$. $\mathrm{Hg}$. Disability was $80 \%$.

Case 30.-Cis. M., aged 39, had worked at Plant M. as a bobbin washer for five years and as a churn cleaner for 11 years. In 1939 he had chronic $\mathrm{CS}_{2}$ poisoning with polyneuritis. He stopped work in 1952, and was admitted to hospital in 1952 with pseudobulbar paralysislike encephalopathy with a right hemiparesis, tremors, and psychic deterioration. Blood pressure was $120 / 75$ $\mathrm{mm}$. $\mathrm{Hg}$. Disability was $80 \%$.

Case 31.-Maz. E., aged 44, had been a bleacher at Plant C. for 23 years. In June, 1952, he had a sudden right hemiparesis for which he was removed from work. He was admitted to hospital in 1952 with a right hemiparesis. An electroencephalogram was indicative of diffuse vascular lesions. Blood pressure was 150/110 mm. Hg. Disability was $25 \%$.

Case 32.-Tag. A., aged 61 , had been a spinner at Plant C. for 23 years. In 1942 he had slight $\mathrm{CS}_{2}$ poisoning, and left work in 1942. He was again at work in 1947 in the staple spinning department from which he was finally removed in January, 1950. His first admission 
to hospital was in 1950 with diffuse encephalopathy with protuberantial focalization at the right side (paralysis VII, paresis V and VIII). He was readmitted to hospital in January, 1952, for right hemiplegia. Blood pressure was $175 / 110 \mathrm{~mm}$. $\mathrm{Hg}$. He died at the hospital. Necropsy revealed atherosclerotic-vascular encephalopathy with multiple foci of encephalomalacia.

Case 33.-San F., aged 53, had been employed at Plant $P$. as a spinner for 24 years. In 1942 he had acute $\mathrm{CS}_{2}$ poisoning and in 1948 signs of slight polyneuritis of the legs. He was removed from work in May, 1952, and admitted to hospital in 1952 with spastic right paraparesis, tremors, and staggering gait. While in the hospital he had a sudden attack of right hemiplegia. Blood pressure varied from $160 / 100$ to $135 / 80 \mathrm{~mm}$. $\mathrm{Hg}$. Disability was $100 \%$.

Case 34.-Poz. R., aged 47, had been a spinner for 18 years at Plant C. In 1942 he had slight polyneuritis from $\mathrm{CS}_{2}$, and in 1951 a sudden right hemiplegia for which he left work. The hemiplegia partially regressed. He was admitted to hospital in 1952 with mild left hemiparesis and signs of polyneuritis (absence of Achilles reflexes). Blood pressure was $150 / 100 \mathrm{~mm}$. $\mathrm{Hg}$. Disability was $30 \%$.

Case 35.-Pra. E., aged 51, had been a rayon bobbin washer at Plant C. for 29 years. From 1950 he suffered from giddiness, difficulty in walking, and severe psychic deterioration. In June, 1952, he had a right hemiparesis for which he was removed from work and admitted to hospital in the same year with diffuse vascular encephalopathy with severe mental deterioration and motor loss, mainly of the right side. Blood pressure was $180 / 110 \mathrm{~mm}$. Hg. Disability was $100 \%$.

Case 36.-Par. M., aged 54, had worked at Plant C. as a spinner for 27 years. In 1949 he had paraesthesias, cramps, and pains in the legs, and left work at the beginning of 1950 . He first admission to hospital was in 1950 with a luetic Parkinson syndrome; blood pressure was $165 / 90 \mathrm{~mm}$. $\mathrm{Hg}$. He was readmitted in 1952 with a Parkinson syndrome, dementia, and a thalamic syndrome with violent pains. Blood pressure was $125 / 85 \mathrm{~mm}$. $\mathrm{Hg}$. Disability was $100 \%$.

Case 37.-Car. A., aged 58, had worked at Plant P. as a churner for 28 years. In 1950 he had signs of polyneuritis and paresis of the left limbs but rapidly improved. In 1951 he had another episode of right paresis for which he left work and was admitted to the Neurological Hospital at Pavia. He was admitted to this Institute in 1952 with a pseudobulbar syndrome. Blood pressure was $200 / 100 \mathrm{~mm}$. Hg. Disability was $40 \%$.

Case 38.-Car. G., aged 51, had been a spinner for 10 years, a bleacher for four years, and then again spinner for another 13 years. From 1947 he had had paraesthesias and weakness of the legs. In October, 1951, he had a left hemiplegia for which he stopped work. He was admitted to hospital in 1952 with diffuse vascular encephalopathy with left hemiparesis, tremors, hypertonia of the legs, and staggering gait. Endocraniotic alterations were visible radiologically. Blood pressure was $125 / 85 \mathrm{~mm}$. Hg. Disability was $100 \%$.

Case 39.-Car. C., aged 64, had worked at Plant C. as a painter in the rayon spinning department for 17 years. In 1945 he had a slight episode of acute $\mathrm{CS}_{2}$ poisoning, and from 1951 progressive weakness of the legs. He was removed from work in July, 1952, and was admitted to hospital in 1952 with initial pseudobulbar syndrome with left hemiparesis, renal atherosclerosis, and obliterating endo-arteritis of the right leg. Blood pressure was $210 / 130 \mathrm{~mm}$. Hg. Disability was $100 \%$.

Case 40.-Cap. D., aged 57, worked for 12 years at the feeding and discharging of the staple bleaching machines. In July, 1951, he had a left hemiparesis for which he left work. He was admitted to hospital in 1952 with alternately the Millard-Gubler syndrome and dementia. Blood pressure was $150 / 90 \mathrm{~mm}$. Hg. Disability was $100 \%$.

Case 41.-Ado. L., aged 47, had been a spinner at Plant C. for 23 years. In 1949 he was first admitted to the hospital with polyneuritis of the legs and central lesions causing considerable intellectual and emotional deterioration. He left work in 1949, and was readmitted to hospital in 1952 . The signs of polyneuritis had disappeared, but he showed remarkable manifestations of psychic deterioration with hysteria-like gestures. Blood pressure was $120 / 80 \mathrm{~mm}$. $\mathrm{Hg}$. Disability was $50 \%$.

Case 42.-Mon. V., aged 58, had worked at Plant C. as a bleacher for six years, and as a rayon bobbin washer for two years. In 1947 a left hemiparesis partly regressed, but severe static and intentional tremor of the limbs remained. He left work at the end of 1951, and was admitted to hospital in 1953 with a right hemiparesis on an atherosclerotic base in a psychoneurotic subject. Blood pressure was $200 / 120 \mathrm{~mm}$. Hg. Disability was $50 \%$.

Case 43.-Vil. G., aged 55, had been a rayon bobbin washer for five years at Plant C. After two years of work he had slight hypertension and a Parkinson hemisyndrome of the right side. He left work in October, 1952, and was admitted to hospital in January, 1953. Parkinsonism was more marked on the right side with central paresis of the right facial nerve. Blood pressure was $185 / 110 \mathrm{~mm}$. $\mathrm{Hg}$. Disability was $70 \%$. 